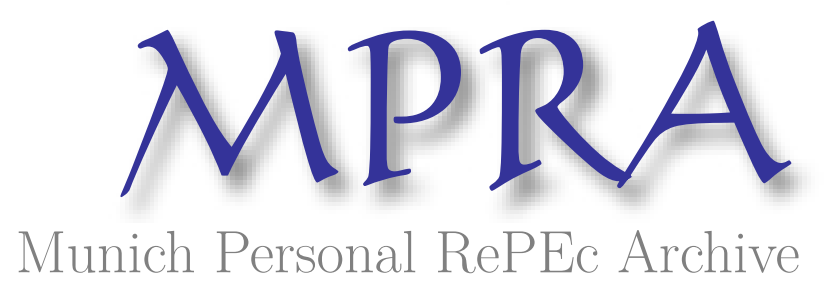

Empirical Study of the effect of including Skewness and Kurtosis in Black Scholes option pricing formula on SP CNX Nifty index Options

Saurabha, Rritu and Tiwari, Manvendra

IIM Lucknow

November 2007

Online at https://mpra.ub.uni-muenchen.de/6329/

MPRA Paper No. 6329, posted 17 Dec 2007 21:03 UTC 


\title{
Empirical Study of the effect of including Skewness and Kurtosis in Black Scholes option pricing formula on S\&P CNX Nifty index Options
}

\author{
Manvendra Tiwari \\ $\&$ \\ Rritu Saurabha \\ IIM Lucknow \\ Prabandh Nagar \\ Lucknow - 226013 \\ India
}

\begin{tabular}{|l|l|l|}
\hline Manvendra Tiwari & mtiwari.iitg@gmail.com & +919956887940 \\
\hline Rritu Saurabha & rsaurabha@gmail.com & +919305077730 \\
\hline
\end{tabular}




\title{
Empirical Study of the effect of including Skewness and Kurtosis in Black Scholes option pricing formula on S\&P CNX NIFTY index Options
}

\begin{abstract}
The most popular model for pricing options, both in financial literature as well as in practice has been the Black-Scholes model. In spite of its wide spread use the model appears to be deficient in pricing deep in the money and deep out of the money options using statistical estimates of volatility. This limitation has been taken into account by practitioners using the concept of implied volatility. The value of implied volatility for different strike prices should theoretically be identical, but is usually seen in the market to vary. In most markets across the world it has been observed that the implied volatilities of different strike prices form a pattern of either a 'smile' or 'skew'. Theoretically, since volatility is a property of the underlying asset it should be predicted by the pricing formula to be identical for all derivatives based on that same asset. Hull [1993] and Nattenburg [1994] have attributed the volatility smile to the non normal Skewness and Kurtosis of stock returns.

Many improvements to the Black-Scholes formula have been suggested in academic literature for addressing the issue of volatility smile. This paper studies the effect of using a variation of the BS model (suggested by Corrado \& Sue [1996] incorporating non-normal skewness and kurtosis) to price call options on S\&P CNX Nifty.

The results strongly suggest that the incorporation of skewness and kurtosis into the option pricing formula yields values much closer to market prices. Based on this result and the fact that this approach does not add any further complexities to the option pricing formula, we suggest that this modified approach should be considered as a better alternative.
\end{abstract}




\section{Introduction}

The most popular model for pricing options, both in financial literature as well as in practice has been the one developed by Fischer Black \& Myron Scholes. In spite of its wide spread use the model appears to be deficient in pricing deep in the money and deep out of the money options using statistical estimates of volatility. This limitation has been taken into account by practitioners using the concept of implied volatility. Implied volatility is the value of statistical volatility needed to be used in the standard Black-Scholes pricing formula for a given strike price to yield the market price of that option. The value of implied volatility for different strike prices should theoretically be identical, but is usually seen in the market to vary. In most markets across the world it has been observed that the implied volatilities of different strike prices form a pattern of either a 'smile' or 'skew'. Theoretically, since volatility is a property of the underlying asset it should be predicted by the pricing formula to be identical for all derivatives based on that same asset. Hull [1993] and Nattenburg [1994] have attributed the volatility smile to the non normal Skewness and Kurtosis of stock returns which is contrary to the assumption of Black-Sholes Model.

Many improvements to the Black-Scholes formula have been suggested in academic literature for addressing the issue of volatility smile. Corrado and Su [1996] have extended the BlackScholes formula to account for non-normal skewness and kurtosis in stock return distributions. Their assumption is that if the volatility smile is due to non-normal skewness and kurtosis of the distribution of asset returns, this should be removed if the effect of this deviations is included in the pricing formula. The method suggested by them for incorporation of this deviation is based on fitting of the first four moments of stock return distribution on to a pattern of empirically observed option prices. The values of implied volatility, implied skewness and implied kurtosis have been estimated by minimizing the error between predicted and actual market option prices for all available strike prices.

In this paper we address the volatility smile pattern as observed in the NSE Nifty index options. This paper is organized into four sections. The first section discusses current and recent literature on this topic. The second and third sections present the applied model and the implementation details. The last section presents the conclusion of this study and the managerial implications thereof. 


\section{Literature Review}

In all major markets across the world differing implied volatilities of options on the same underlying asset across different exercise prices and terms to maturity have been observed. In a recent study on the NSE NIFTY, Misra, Kannan and Misra [2006] have reported a significant volatility smile on NIFTY options. The results of their study show that deep in the money and deep out of the money options have higher volatility than at the money options and that the implied volatility of OTM call options is greater than ITM calls. Daily returns of the NSE NIFTY have been found to follow normal distribution with some Skewness and Kurtosis. These results suggest that the volatility smile observed in the NSE NIFTY options can be explained in some measure by the observed Skewness and Kurtosis.

To incorporate the effects of non-normal skewness and kurtosis into the Black-Scholes option pricing formula, Hermite polynomials have been used to get an expansion of the probability density function adjusted for skewness and kurtosis. Usually, this series is called Gram-Charlier. For practical purposes, only the first few terms of this expansion are taken into consideration. The resulting truncated series may be viewed as the normal probability density function multiplied by a polynomial that accounts for the effects of departure from normality. The GramCharlier series uses the moments of the real distribution. The Edgeworth series is similar to Gram-Charlier but uses cumulants instead of moments. Although the series are equivalent, for computational purposes the Gram-Charlier series seems to perform better than the Edgeworth series [Johnson et al., 1994].

This approach was introduced in financial economics by Jarrow and Rudd [1982], and it has been applied by Madan and Milne [1994], Longstaff [1995], Abken et al. [1996a ; 1996b], Brenner and Eom [1997], Knight and Satchell [1997], Backus et al. [1997], Corrado and Su [1997].

Jarrow and Rudd [1982] proposed a semi-parametric option pricing model to account for observed strike price biases in the Black-Scholes model. They derived an option pricing formula from an Edgeworth expansion of the lognormal probability density function to model the distribution of stock prices. Corrado and $\mathrm{Su}$ [1996] have adapted this extension developed by Jarrow and Rudd to extend the Black-Scholes formula to account for non-normal skewness and kurtosis in stock returns. While following the same methodology they used a Gram-Charlier 
series expansion of the normal probability density function to model the distribution of stock $\log$ prices. This method fits the first four moments of a distribution to a pattern of empirically observed option prices. The mean of this distribution is determined by option pricing theory, but an estimation procedure is employed to yield implied values for the standard deviation, skewness and kurtosis of the distribution of stock index prices. We have used the extended formula adapted by Corrado and Su [1996] for the NSE NIFTY index options to address the volatility smile reported.

\section{Framework/Model Applied}

Corrado and $\mathrm{Su}$ [1996] have developed a method to incorporate effects of non-normal skewness and kurtosis of asset returns into an expanded Black-Scholes option pricing formula (Brown et. al. [2002] suggested a correction to this approach which was incorporated in Corrado and $\mathrm{Su}$ [1997]). Their method adapts a Gram-Charlier series expansion of the standard normal density function to yield an option price formula which is the sum of Black-Scholes option price plus two adjustment terms for non-normal skewness and kurtosis. Specifically, the density function $\mathrm{g}(\mathrm{z})$ defined below accounts for non-normal skewness and kurtosis, denoted by $\mu_{3}$ and $\mu_{4}$, respectively, where $\mathrm{n}(\mathrm{z})$ represents the standard normal density function.

$$
g(z)=n(z)\left[1+\frac{\mu_{3}}{3 !}\left(z^{3}-3 z\right)+\frac{\mu_{4}-3}{4 !}\left(z^{4}-6 z^{2}+3\right)\right]
$$

Where,

$$
z=\frac{\ln \left(S_{t} / S_{o}\right)-\left(\mathrm{r}-\frac{\sigma^{2}}{2}\right) \mathrm{t}}{\sigma \sqrt{t}}
$$

And,

$\mathrm{S}_{\mathrm{o}} \quad$ is the current asset price

$\mathrm{S}_{\mathrm{t}} \quad$ is the stochastic asset price at time $\mathrm{t}$

$\mathrm{r} \quad$ is the risk free rate of interest

$\sigma \quad$ is the standard deviation of the returns for the underlying asset 
In the formula above, skewness $\mu_{3}$ and kurtosis $\mu_{4}$ have been explicitly used in the density function $\mathrm{g}(\mathrm{z})$ in the functional form. For the normal distribution curve the values of these coefficients are: skewness $\mu_{3}=0$; and kurtosis $\mu_{4}=3$.

Using the function $g(z)$, the value of the theoretical call price as the present value of the expected payoff at option expiration has been found out to be:

$$
C=e^{-r t} \int_{K}^{\infty}\left(S_{t}-K\right) g\left(z\left(S_{t}\right)\right) d z\left(S_{t}\right)
$$

Where,

$\mathrm{K}$ is the strike price

$z\left(S_{t}\right)=\left(\log S_{t}-\mu\right) / \sigma \sqrt{t}$

$\mu=\log S_{0}+\left(r-\frac{\sigma^{2}}{2}\right) t$

The above integral can be evaluated using the Gram-Charlier density expansion, and the evaluated option price is denoted as $C_{G C}$ while the Black-Scholes option price formula is denoted as $C_{B S}$.

$$
\begin{gathered}
C_{B S}=S_{o} N(d)-K e^{-r t} N(d-\sigma \sqrt{t}) \\
d=\frac{\ln \left(S_{o} / K\right)+\left(\mathrm{r}+\frac{\sigma^{2}}{2}\right) \mathrm{t}}{\sigma \sqrt{t}} \\
C_{G C}=C_{B S}+\mu_{3} Q_{3}+\left(\mu_{4}-3\right) Q_{4}
\end{gathered}
$$

Where,

$$
\begin{aligned}
& Q_{3}=\frac{1}{3 !} S_{o} \sigma \sqrt{t}\left((2 \sigma \sqrt{t}-d) n(d)+\sigma^{2} t N(d)\right) \\
& Q_{4}=\frac{1}{4 !} S_{o} \sigma \sqrt{t}\left(\left(d^{2}-1-3 \sigma \sqrt{t}(d-\sigma \sqrt{t}) n(d)+\sigma^{3} t^{3 / 2} N(d)\right)\right.
\end{aligned}
$$


In the adjusted formula, the terms $\mu_{3} Q_{3}$ and $\left(\mu_{4}-3\right) Q_{4}$ measure the effect of the non-normal skewness and kurtosis on the option price $C_{G C}$.

For this study, we have used both the Black-Scholes formula and the modified formula as suggested by Corrado and $\mathrm{Su}$ [1996] to calculate option prices. Thereafter, the error in both cases has been calculated and tested for statistically significant difference using paired ' $t$ ' test.

\section{Empirical Study}

We started the study by testing the fact that the Nifty closing values do not follow a lognormal distribution and that Nifty returns do not conform to the normal distribution. Figure 1 shows the frequency plot of Nifty closing values.

For the examination, we have computed the mean, standard deviation, skewness and kurtosis of the daily and weekly NSE Nifty returns since its inception. The values are reported in Table 1. The distribution of the returns is shown in Figure $2 \boldsymbol{\&} \mathbf{3}$ and is superimposed with the normal distribution of identical mean and variance for better comparison.

From this analysis it can be observed that the distribution of Nifty returns has a negative skew and positive kurtosis as expected and reported for most markets across the world. After confirming significant skewness and kurtosis in the returns, the Black-Scholes formula and the skewness and kurtosis adjusted formula have been applied for prediction of option prices.

Thereafter, the analysis was based on call prices of Nifty Options (European type) for the period of about three months from $1^{\text {st }}$ August 2007 to $24^{\text {th }}$ October 2007. Data for thinly traded options (less than 100 contracts on a given day) was excluded from the study. 


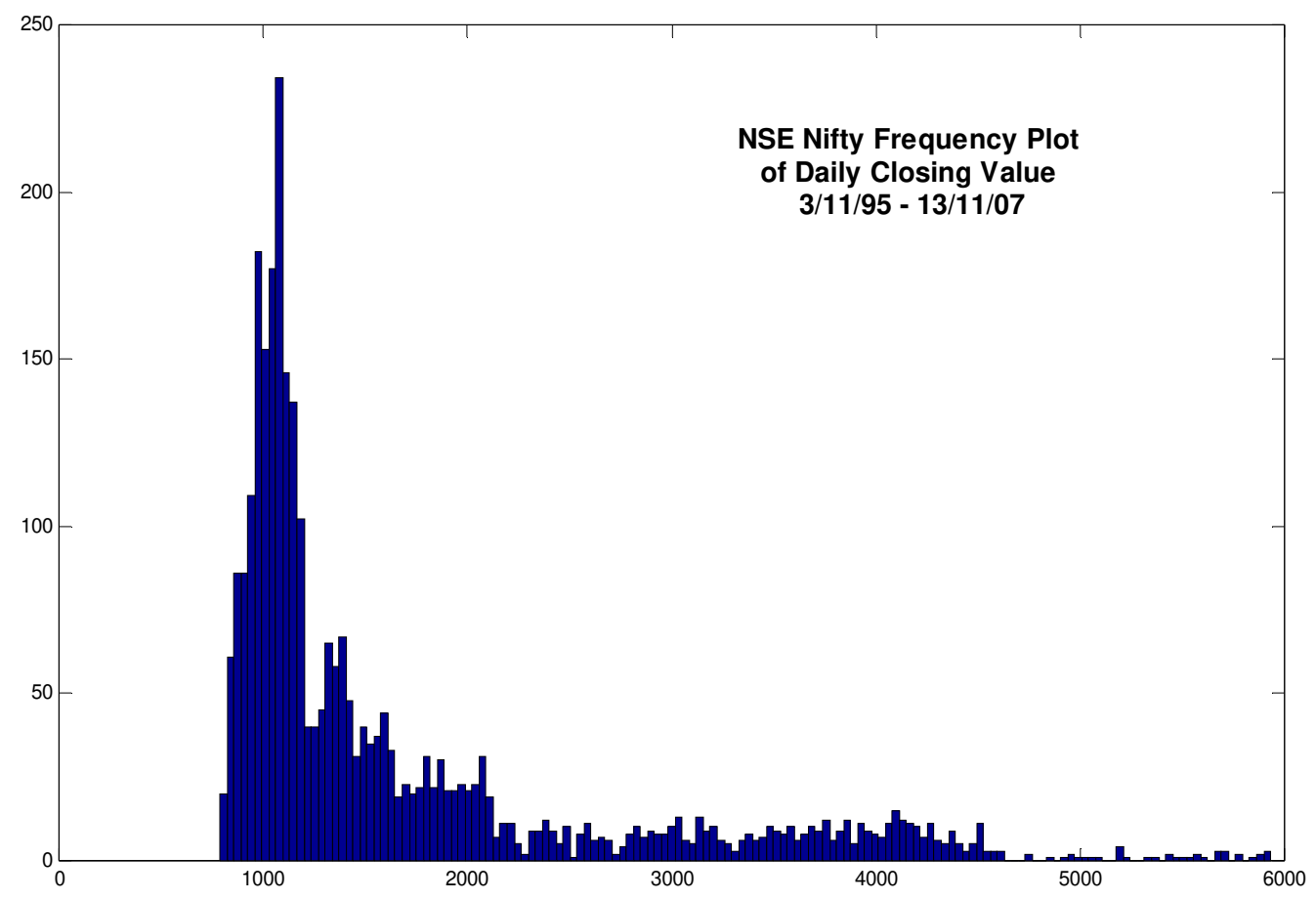

Figure 1: NSE Nifty Frequency of Closing Values

\begin{tabular}{|c|c|c|}
\hline NSE Nifty & Daily Returns & Weekly Returns \\
\hline Mean & 0.0006 & 0.0023 \\
\hline Std. Dev. & 0.016 & 0.033 \\
\hline Skewness & -0.3168 & -0.3334 \\
\hline Kurtosis & 4.4682 & 1.7953 \\
\hline
\end{tabular}

Table 1: NSE Nifty Returns Data 


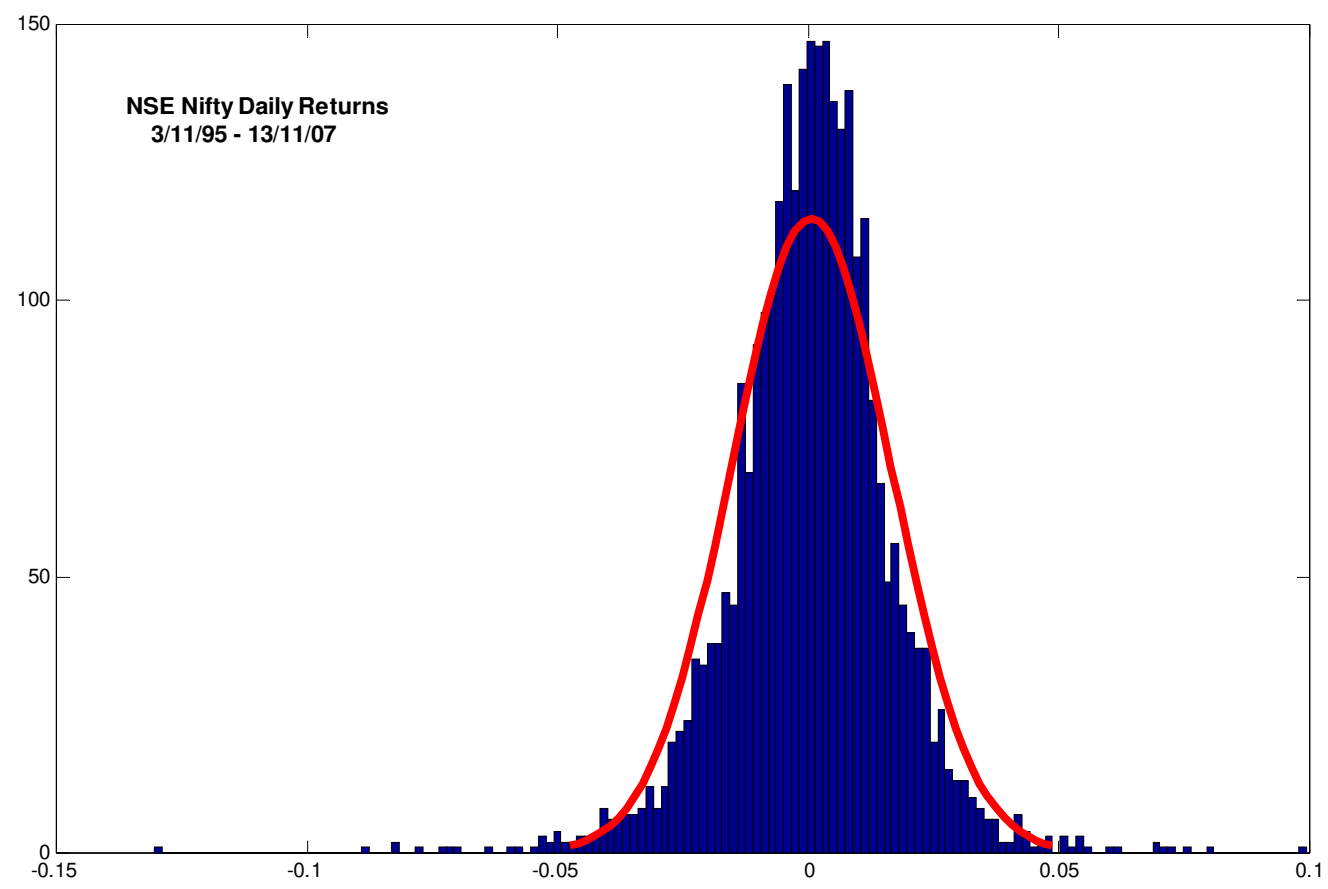

Fig.: 2: NSE Nifty Frequency Plot of Daily Returns (3/11/95 - 13/11/97)

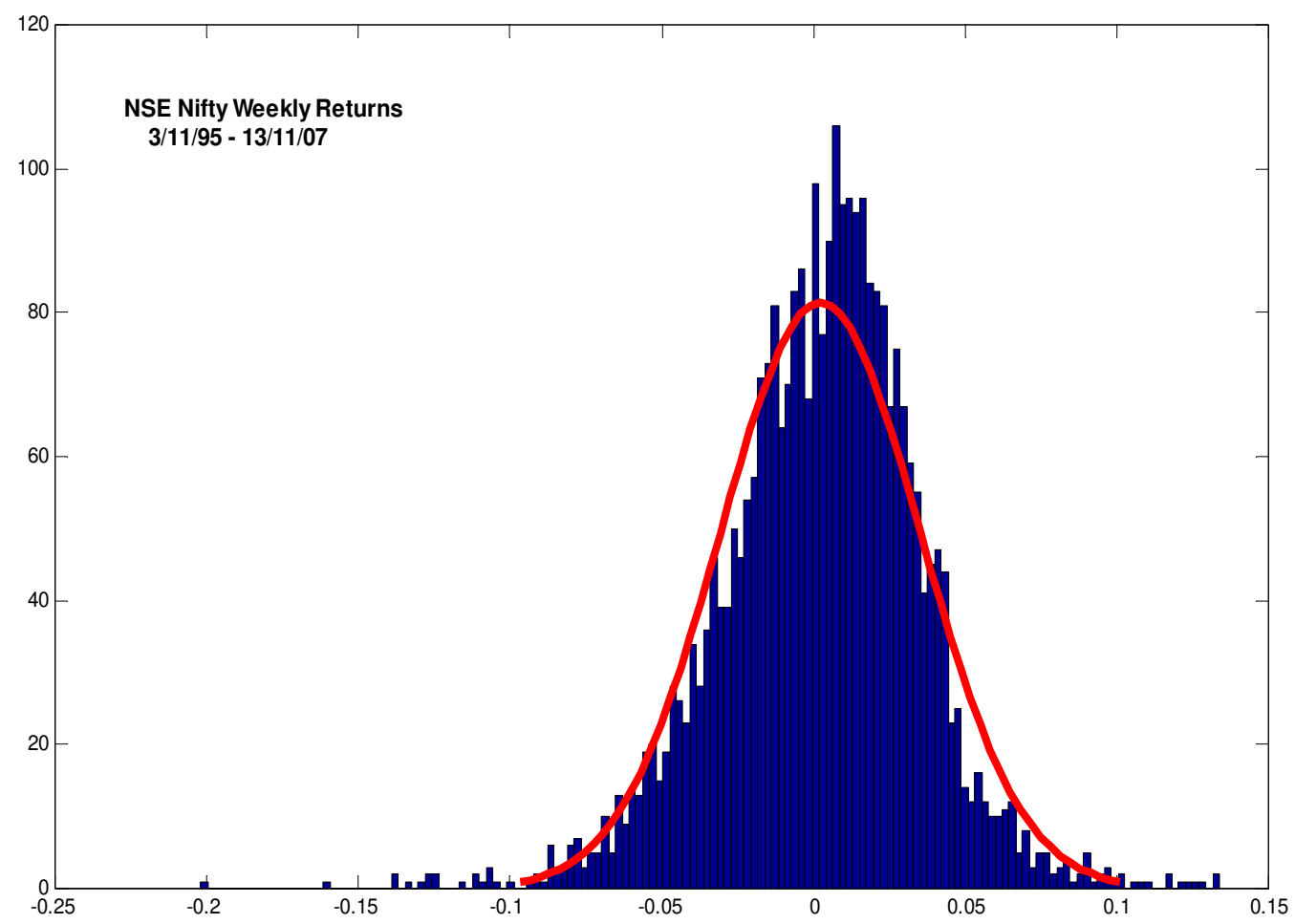

Fig.: 3: NSE Nifty Frequency Plot of Weekly Returns (3/11/95 - 13/11/97) 


\section{Methodology}

\section{The Black Scholes option pricing formula}

The four parameters of Black-Scholes option pricing formula namely, stock price, strike price, time to option maturity and the risk free interest rate have been directly observed form the market. The daily MIBOR (Mumbai Inter Bank Offer Rate) rate has been taken as the risk free interest rate. Another input to the formula is the standard deviation of stock price. This should theoretically be identical for options of all strike prices because the underlying asset is the same in each case. But, since this is not directly observable, it has been estimated using the following method -

Using option prices for all contracts within a given maturity series observed on a given day, we estimate a single implied standard deviation to minimize the total error sum of squares between the predicted and the market prices of options of various strike prices. This has been calculated using Microsoft Excel Solver function by minimizing the following function by iteratively changing the implied standard deviation.

$$
\min _{B S I S D} \sum_{j=1}^{N}\left[C_{O B S, j}-C_{B S, j}(B S I S D)\right]^{2}
$$

Where BSISD stands for the Black-Scholes Implied Standard Deviation

After all the input variables for the model are obtained, they are used to calculate theoretical option prices for all strikes within the same maturity series for the following day. Thus theoretical option prices for a given day are based on a prior-day, out-of sample implied standard deviation estimate. We then compare these theoretical prices with the actual market prices observed on that day.

\section{Skewness and Kurtosis adjusted Black-Sholes option pricing formula}

Next, we assess the skewness and kurtosis adjusted Black-Scholes option pricing formula developed by Jarrow and Rudd [1982] using an analogous procedure. Specifically, on a given day we estimate a single implied standard deviation, a single skewness coefficient, and a single excess kurtosis coefficient by minimizing once again the error sum of squares represented by the following formula. 


$$
\min _{I S D, I S K, I S T} \sum_{j=1}^{N}\left[C_{O B S, j}-\left(C_{B S, j}(I S D)+I S K * Q_{3}+(I K T-3) * Q_{4}\right)\right]^{2}
$$

Where ISD, ISK and IKT represent estimates of the implied standard deviation, implied skewness and implied kurtosis parameters based on $\mathrm{N}$ price observations.

We then use these three parameter estimates as inputs to the Jarrow-Rudd formula to calculate theoretical option prices corresponding to all option prices within the same maturity series observed on the following day. Thus these theoretical option prices for a given day are based on prior-day, out-of-sample implied standard deviation, skewness, and excess kurtosis estimates. We then compare these theoretical prices with the actual market prices observed on that day.

\section{Hypothesis:}

The total error in prediction of option prices for various strike prices by the modified Black Scholes method is less than that by the original Black Scholes method.

\section{Comparison:}

The theoretical option prices thus generated using the two approaches are then compared with their actual market prices. For comparison, we compute the Error Sum of Squares (ESS) for the two approaches by summing the square of the difference between the predicted and the actual prices. These two ESS are then compared for statistically significant difference using the paired ' $\mathrm{t}$ ' test.

\section{Results:}

The paired ' $t$ ' test of the samples of ESS results in a ' $t$ ' statistic value of 7.57 which overwhelmingly rejects the hypothesis that the errors in prediction of option prices by the two methods are not significantly different.

We also do the comparison test independently for options of all four maturities. The ' $t$ ' statistic values in case of each of the four separate tests are greater than the critical value for $95 \%$ confidence level. Hence we can see that the modified Black-Scholes formula appears to price Nifty options much closer to the actual market prices.

Figure 4 shows the calculated implied volatilities using the two methods. Black-Scholes implied volatilities are the usual volatilities required to be inserted into the BS formula so that it gives the market price of the option. For the modified Black-Scholes method, the skewness and kurtosis 
have been kept constant and equal to that obtained upon reducing the total error in pricing of options of all strikes for a given maturity for that day (as explained in methodology), and then the volatilities have been calculated as those required to be inserted into the modified BS formula so that it gives the market price of the option.

The volatility smile as observed for the BS model is significant, while that for the modified model the implied volatility curve is almost flat.

The detailed results tables are as follows:

\begin{tabular}{|lrr|}
\hline t-Test: Paired Two Sample for Means & \\
\hline & & \\
\hline & BS Original & BS Modified \\
\hline Mean & 20598.15661 & 2307.040835 \\
\hline Variance & 342544637.2 & 10664366.58 \\
\hline Observations & 60 & 60 \\
\hline Pearson Correlation & 0.024857351 & \\
Hypothesized Mean Difference & 0 & \\
\hline Df & 59 \\
\hline t Stat & $\mathbf{7 . 5 7 1 0 3 2 7 7 9}$ \\
\hline $\mathrm{P}(\mathrm{T}<=\mathrm{t})$ one-tail & $1.45726 \mathrm{E}-10$ \\
\hline $\mathrm{t}$ Critical one-tail & 1.671093033 \\
\hline $\mathrm{P}(\mathrm{T}<=\mathrm{t})$ two-tail & $2.91451 \mathrm{E}-10$ \\
\hline $\mathrm{t}$ Critical two-tail & 2.000995361 & \\
\hline
\end{tabular}

Table 2: Paired ' $t$ ' test results (combined for all strike prices) 
t-Test: Paired Two Sample for Means - 30th Aug

\begin{tabular}{|lrr|}
\hline & BS Original & BS Modified \\
\hline Mean & 20340.74418 & 1302.505601 \\
\hline Variance & 424366615.5 & 1382374.835 \\
\hline Observations & 10 & 10 \\
\hline Pearson Correlation & -0.55641946 \\
& & \\
Hypothesized Mean Difference & 0 \\
\hline Df & 9 \\
\hline t Stat & $\mathbf{2 . 8 2 9 5 6 9 0 9 7}$ \\
\hline P $(T<=t)$ one-tail & 0.009868142 \\
\hline t Critical one-tail & 1.833112923 \\
\hline P $(T<=t)$ two-tail & 0.019736283 \\
\hline$t$ Critical two-tail & 2.262157158 \\
\hline
\end{tabular}

\section{t-Test: Paired Two Sample for Means - 25th Oct}

\begin{tabular}{|lrr|}
\hline & BS Original & BS Modified \\
\hline Mean & 18908.97069 & 3382.171758 \\
\hline Variance & 192781467.8 & 19322125.72 \\
\hline Observations & 20 & 20 \\
\hline Pearson Correlation & -0.13652606 \\
\hline & 0 & \\
Hypothesized Mean Difference & 19 \\
Df & $\mathbf{4 . 5 9 0 9 0 9 3 1}$ \\
t Stat & $9.97638 \mathrm{E}-05$ \\
\hline $\mathrm{P}(\mathrm{T}<=\mathrm{t})$ one-tail & 1.729132792 \\
\hline t Critical one-tail & 0.000199528 \\
\hline $\mathrm{P}(\mathrm{T}<=\mathrm{t})$ two-tail & 2.09302405 \\
\hline t Critical two-tail &
\end{tabular}

t-Test: Paired Two Sample for Means - 27th Sep

\begin{tabular}{lrr}
\hline & BS Original & BS Modified \\
\hline Mean & 30932.3018 & 1982.878403 \\
\hline Variance & 389184830 & 5497910.873 \\
\hline Observations & 20 & 20 \\
\hline Pearson Correlation & 0.2606916 & \\
Hypothesized Mean & \multicolumn{2}{|c}{} \\
Difference & 0 & \\
df & 19 & \\
t Stat & $\mathbf{6 . 7 2 5 4 6 9 7 9}$ & \\
P $(\mathrm{T}<=\mathrm{t})$ one-tail & $9.958 \mathrm{E}-07$ & \\
t Critical one-tail & 1.72913279 & \\
P $(\mathrm{T}<=\mathrm{t})$ two-tail & $1.9916 \mathrm{E}-06$ & \\
t Critical two-tail & 2.09302405 & \\
\hline
\end{tabular}

\section{t-Test: Paired Two Sample for Means - 29th Nov}

\begin{tabular}{|lrr|}
\hline & BS Original & BS Modified \\
\hline Mean & 3565.65045 & 1809.639087 \\
\hline Variance & 26532333.2 & 11932312.04 \\
\hline Observations & 10 & 10 \\
\hline Pearson Correlation & 0.96883806 \\
\hline $\begin{array}{l}\text { Hypothesized Mean } \\
\text { Difference }\end{array}$ & 0 \\
\hline df & 9 & \\
t Stat & $\mathbf{2 . 7 8 0 8 4 3 7 8}$ \\
\hline $\mathrm{P}(\mathrm{T}<=\mathrm{t})$ one-tail & 0.01068564 \\
\hline $\mathrm{t}$ Critical one-tail & 1.83311292 & \\
\hline $\mathrm{P}(\mathrm{T}<=\mathrm{t})$ two-tail & 0.02137127 & \\
$\mathrm{t}$ Critical two-tail & 2.26215716 & \\
\hline
\end{tabular}

Table 3: Paired 't' test results (separately for different strike prices) 


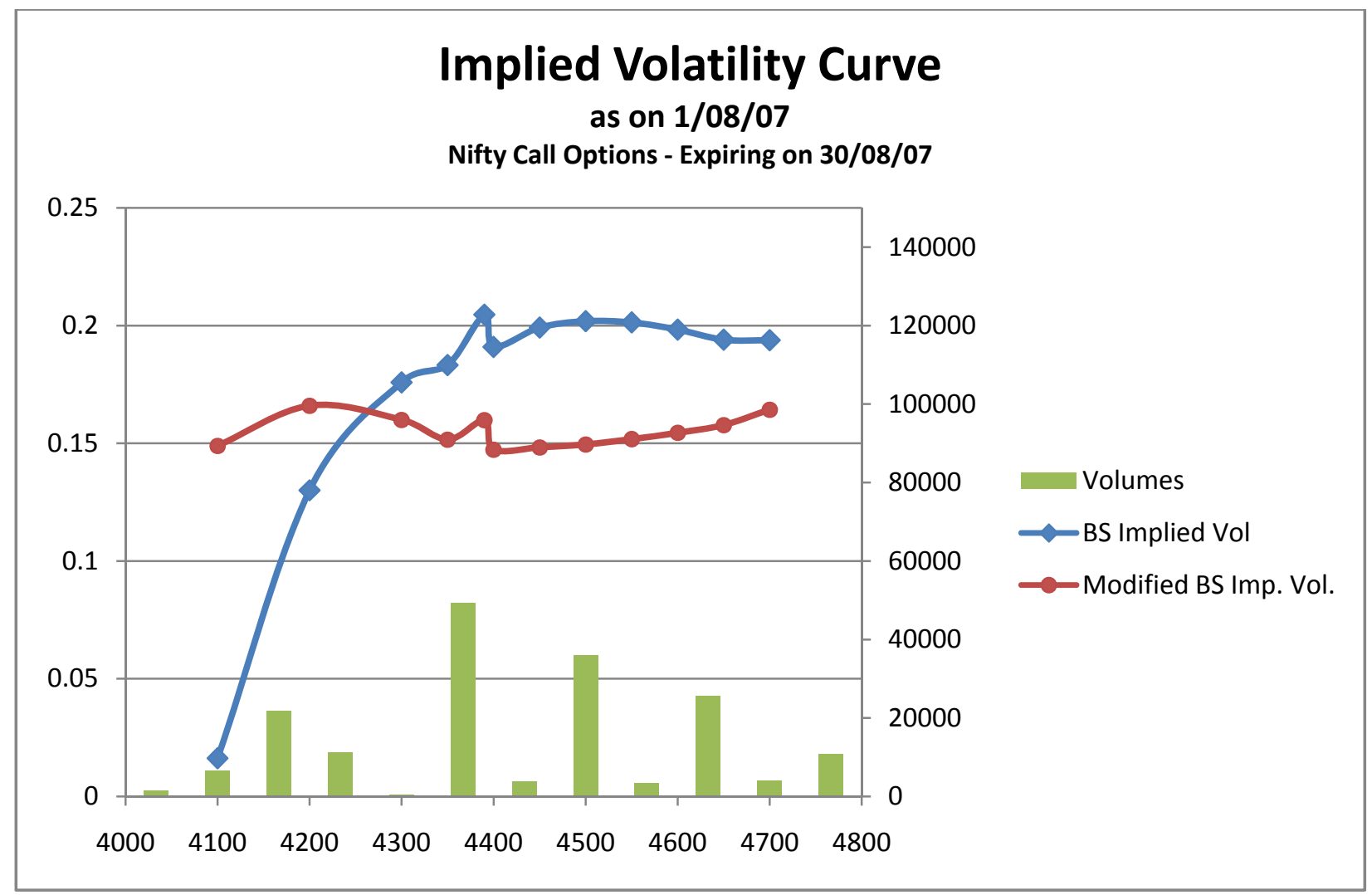

Figure 4: Implied Volatility Curve (BS and Modified BS) for Nifty Call Options on 1/08/07

For the Modified BS curve, Skewness $=2.13 \&$ Kurtosis $=-2.44$

\section{Conclusion and managerial/policy implications}

The results obtained from the analysis confirm our hypothesis that the modified Black-Scholes model as put forward by Corrado \& Su performs significantly better for NSE Nifty option prices. We also see that the calculation process in the modified model is not very different from the Black-Scholes model. Since it does not add unnecessary complexity and still gives significantly better predictions of option prices, we recommend that this modified model should be looked at as a better alternative to the existing method.

This study also confirms that fitting of higher order moments of the distribution of returns is important, especially for options away from the money. 
Figure 4 shows the implied volatility curve for both the methods. It graphically shows that the 'smile' of the implied volatility curve can be significantly explained by the implied skewness and kurtosis of the reduced by using the modified BS formula.

This study also shows a way towards further work in this area. In this study, we have calculated implied volatility, skewness and kurtosis based on today's data to predict tomorrow's prices. This can be extended to explore whether the modified approach gives significantly better prices for longer durations or not. A related study could be regarding comparison of returns achieved using trading strategies based on these two different models. It would be interesting to see if significant gains can be made using the modified BS model over the original model. 


\section{References}

1. Data on option prices, Retrieved October 30, 2007 from http://www.nseindia.com/

2. Barone-Adesi, G. and R.E. Whaley (1986): "The Valuation of American Call Options and the Expected Ex-Dividend Stock Price Decline," Journal of Financial Economics, 17:91-111.

3. Black, F. and Scholes, M. (1973): "The Pricing of Options and Corporate Liabilities," Journal of Political Economy, 81:637-659.

4. Black, F. (1975): "Fact and Fantasy in the Use of Options," Financial Analysts Journal, 31:36-72.

5. Brown, Christine A. and Robinson, David M. (2002): "Skewness and kurtosis implied by option prices: A correction," Journal of Financial Research, Vol. XXV No. 2, 279-282.

6. Corrado, C. and Sue, T. (1997): "Implied Volatility Skews and Stock Index Skewness and Kurtosis in S\&P 500 Index Option Prices," European Journal of Finance, Vol. 3 No. 1, 73-85.

7. Corrado, C. and Sue, T. (1996): "Skewness and Kurtosis in S\&P 500 Index Returns Implied by Option Prices," Journal of Financial Research, Vol. XIX No. 2, 175-192.

8. Corrado, C. and Sue, T. (1996): "S\&P 500 Index Option Tests of Jarrow and Rudd's Approximate Option Valuation Formula," Journal of Futures Markets, Vol. 16 No. 6, 611-629.

9. Hull, J.C. (1993): Options, Futures, and Other Derivative Securities, Englewood Cliffs, N.J.: Prentice Hall.

10. Jarrow, R. and Rudd, A. (1982): "Implied Volatility Skews and Skewness and Kurtosis In Stock Option Prices," Journal of Financial Economics, 10:347-369.

11. Longstaff, F. A. (1995): "Option pricing and the martingale restriction," Review of Financial Studies, 8(4):1091-1124.

12. Madam, D. and Milne, F. (1991): "Option pricing with VG martingale components," Mathematical Finance, 39-55

13. Misra, D., Kannan,R. and Misra, Sangeeta D. (2006): "Implied Volatility Surfaces: A study of NSE Nifty Options," International Research Journal of Finance \& Economics.

14. Merton, R.C. (1973): "The Theory of Rational Option Pricing," Bell Journal of Economics and Management Science, 4:141-183.

15. Nattenburg, S. (1994): Option Volatility and Pricing, Chicago: Probus Publishing.

16. Rubinstein, M. (1994): "Implied Binomial Trees," Journal of Finance, 49:771-818.

17. Stuart, A. and Ord, J.K. (1987): Kendall's Advanced Theory of Statistics, New York: Oxford University Press.

18. Whaley, R.E. (1982): "Valuation of American Call Options on Dividend Paying Stocks," Journal of Financial Economics, 10:29-58. 


\section{Appendix 'A' - Data on Volatility Smile}

\begin{tabular}{|l|r|r|r|r|r|r|r|}
\hline Date & Expiry & $\begin{array}{l}\text { Strike } \\
\text { Price }\end{array}$ & $\begin{array}{l}\text { BS Implied } \\
\text { Vol }\end{array}$ & $\begin{array}{l}\text { Modified BS } \\
\text { Imp. Vol. }\end{array}$ & Volumes & $\begin{array}{l}\text { BS Mod Imp } \\
\text { Skew }\end{array}$ & \multicolumn{1}{l|}{$\begin{array}{l}\text { BS Mod Imp } \\
\text { Kurt }\end{array}$} \\
\hline 01-Aug-07 & 30-Aug-07 & 4100 & 0.0162 & 0.148910961 & 1448 & 4.63819567 & 1.138337607 \\
\hline 01-Aug-07 & 30-Aug-07 & 4200 & 0.130055461 & 0.165977733 & 6628 & 1.997287203 & 3.001311393 \\
\hline 01-Aug-07 & 30-Aug-07 & 4300 & 0.175867395 & 0.159943408 & 21800 & 2.009064915 & 2.986649372 \\
\hline 01-Aug-07 & 30-Aug-07 & 4350 & 0.183203284 & 0.151586922 & 11183 & 2.000371554 & 2.999023259 \\
\hline 01-Aug-07 & 30-Aug-07 & 4390 & 0.204689112 & 0.159854501 & 443 & 2.006943806 & 2.989818834 \\
\hline 01-Aug-07 & 30-Aug-07 & 4400 & 0.190901711 & 0.147323983 & 49270 & 2.000230589 & 2.999689689 \\
\hline 01-Aug-07 & 30-Aug-07 & 4450 & 0.19914362 & 0.14826732 & 3789 & 1.997030102 & 3.005560229 \\
\hline 01-Aug-07 & 30-Aug-07 & 4500 & 0.201871418 & 0.149495946 & 35965 & 1.95800107 & 3.057268601 \\
\hline 01-Aug-07 & 30-Aug-07 & 4550 & 0.201336728 & 0.151756237 & 3497 & 1.801023346 & 3.137984053 \\
\hline 01-Aug-07 & 30-Aug-07 & 4600 & 0.198280889 & 0.154485538 & 25647 & 1.649510342 & 4.0545701 \\
\hline 01-Aug-07 & 30-Aug-07 & 4650 & 0.193998608 & 0.157726943 & 4129 & 1.386723803 & 5.506102777 \\
\hline 01-Aug-07 & 30-Aug-07 & 4700 & 0.193757333 & 0.164291497 & 10814 & 1.181957805 & 4.921665971 \\
\hline
\end{tabular}




\section{Appendix 'B' - Error Sum of Squares (both approaches) for the days on which option prices are predicted based on last day's data}

\begin{tabular}{|c|c|c|c|c|c|c|c|}
\hline \multirow[b]{2}{*}{ Date } & \multirow[b]{2}{*}{ Expiry } & \multicolumn{2}{|c|}{ Black Scholes Method } & \multicolumn{4}{|c|}{ Modified Black Scholes Method } \\
\hline & & Error & Volatility & Error & Volatility & Skewness & Kurtosis \\
\hline 02-Aug-07 & 30-Aug-07 & 60927.04942 & 0.185121765 & 97.32835152 & 0.153913651 & 2.133776387 & -2.441662433 \\
\hline 06-Aug-07 & 30-Aug-07 & 39604.39956 & 0.173739545 & 914.3397652 & 0.160598894 & 1.210660684 & -4.225859386 \\
\hline 08-Aug-07 & 30-Aug-07 & 38326.3267 & 0.196681537 & 571.4732793 & 0.183089493 & 1.271304849 & -2.984777628 \\
\hline 10-Aug-07 & 30-Aug-07 & 30481.28412 & 0.213455491 & 898.2077131 & 0.16358353 & 1.028276584 & -4.059784161 \\
\hline 14-Aug-07 & 30-Aug-07 & 13291.71849 & 0.237645487 & 459.5281112 & 0.204639867 & 0.950000204 & -0.195634945 \\
\hline 17-Aug-07 & 30-Aug-07 & 5052.086997 & 0.285664629 & 4257.804148 & 0.213343235 & 0.304324055 & 0.216262002 \\
\hline 21-Aug-07 & 30-Aug-07 & 1991.894706 & 0.31349603 & 1041.299202 & 0.305517736 & 0.297634462 & 2.867832614 \\
\hline 23-Aug-07 & 30-Aug-07 & 2495.495556 & 0.324967867 & 1201.377308 & 0.318174196 & -0.14275884 & 4.630263535 \\
\hline 27-Aug-07 & 30-Aug-07 & 4477.808672 & 0.252838284 & 2055.110569 & 0.300983547 & -0.030773994 & 3.524009033 \\
\hline 29-Aug-07 & 30-Aug-07 & 6759.377573 & 0.203734698 & 1528.587567 & 0.221626403 & 0.268942068 & 2.639804032 \\
\hline 02-Aug-07 & 27-Sep-07 & 24545.5972 & 0.191765495 & 1273.51681 & 0.187315757 & 2.009737929 & 2.989815228 \\
\hline 06-Aug-07 & 27-Sep-07 & 27625.4738 & 0.188598911 & 495.5861234 & 0.171705501 & 1.997653383 & 3.003895318 \\
\hline 08-Aug-07 & 27-Sep-07 & 14389.47524 & 0.20624162 & 134.9406774 & 0.172402576 & 1.270817244 & -1.367706694 \\
\hline 10-Aug-07 & 27-Sep-07 & 30918.05662 & 0.208012031 & 1416.435846 & 0.152661136 & -0.073796567 & -2.463725386 \\
\hline 14-Aug-07 & 27-Sep-07 & 14957.31591 & 0.227459773 & 540.2406074 & 0.203200152 & 0.410949443 & -0.211781326 \\
\hline 17-Aug-07 & 27-Sep-07 & 7883.952548 & 0.279622797 & 2727.785768 & 0.331290893 & -0.652350316 & 10.86069605 \\
\hline 21-Aug-07 & 27-Sep-07 & 5047.711927 & 0.28935602 & 637.1112978 & 0.322711979 & -0.493129007 & 4.556720639 \\
\hline 23-Aug-07 & 27-Sep-07 & 9241.406586 & 0.269242499 & 1369.384506 & 0.357319115 & -0.876827836 & 7.276004416 \\
\hline 27-Aug-07 & 27-Sep-07 & 13192.93678 & 0.241965057 & 928.7633029 & 0.355687202 & -0.977988769 & 8.576923242 \\
\hline 29-Aug-07 & 27-Sep-07 & 19683.2513 & 0.212769884 & 1729.637639 & 0.690747595 & -2.266262029 & 17.21665822 \\
\hline 31-Aug-07 & 27-Sep-07 & 50487.60887 & 0.187153381 & 2617.945979 & 0.186128974 & 1.051971388 & -0.494280462 \\
\hline 04-Sep-07 & 27-Sep-07 & 79457.12284 & 0.187578787 & 2893.348446 & 0.174480048 & 0.465772816 & -1.484379269 \\
\hline 06-Sep-07 & 27-Sep-07 & 47443.87677 & 0.168655006 & 3376.0764 & 0.162594612 & 1.041245525 & -2.644880322 \\
\hline 10-Sep-07 & 27-Sep-07 & 46967.91405 & 0.169294233 & 913.9482611 & 0.171923206 & -0.110640111 & 1.387471659 \\
\hline $12-S e p-07$ & 27-Sep-07 & 28298.00761 & 0.211085038 & 371.1404513 & 0.206896848 & -0.339116563 & 2.285022148 \\
\hline 14-Sep-07 & 27-Sep-07 & 34601.81409 & 0.218454552 & 260.3347116 & 0.201178654 & -0.150590446 & 0.523953447 \\
\hline 18-Sep-07 & 27-Sep-07 & 30979.72138 & 0.25467181 & 975.4562652 & 0.212364379 & -0.684492897 & 2.893715221 \\
\hline 20-Sep-07 & 27-Sep-07 & 40782.52379 & 0.23760712 & 10487.03638 & 0.281737588 & -0.940859816 & 7.669125836 \\
\hline 24-Sep-07 & 27-Sep-07 & 66787.28664 & 0.230107453 & 1587.041933 & 0.174691159 & 0.20653119 & 0.47705759 \\
\hline 26-Sep-07 & 27-Sep-07 & 25354.98234 & 0.313028904 & 4921.836667 & 0.196094293 & 0.185791029 & 1.278697089 \\
\hline 06-Aug-07 & 25-Oct-07 & 13572.33457 & $2.26909 \mathrm{E}-24$ & 54.42775868 & 0.182696846 & 0.886052145 & 3.047513507 \\
\hline 27-Aug-07 & 25-Oct-07 & 34.31395316 & 0.235429191 & 49.13358529 & 0.318038088 & -0.818132226 & 1.740351362 \\
\hline 30-Aug-07 & 25-Oct-07 & 12907.07854 & 0.201130594 & 15.56056892 & 0.305265361 & 2.260098004 & 2.837924755 \\
\hline 03-Sep-07 & 25-Oct-07 & 8358.235683 & 0.189943518 & 78.77873965 & 0.111195223 & -2.49134533 & -16.92834634 \\
\hline 05-Sep-07 & 25-Oct-07 & 15024.16326 & 0.182693215 & 113.8009676 & 0.189859232 & -0.300374473 & 2.08864019 \\
\hline
\end{tabular}




\begin{tabular}{|c|c|c|c|c|c|c|c|}
\hline \multirow[b]{2}{*}{ Date } & \multirow[b]{2}{*}{ Expiry } & \multicolumn{2}{|c|}{ Black Scholes Method } & \multicolumn{4}{|c|}{ Modified Black Scholes Method } \\
\hline & & Error & Volatility & Error & Volatility & Skewness & Kurtosis \\
\hline 07-Sep-07 & 25-Oct-07 & 15512.35963 & 0.17962645 & 16.74290491 & 0.162033309 & -0.150605651 & -0.410715423 \\
\hline 11-Sep-07 & 25-Oct-07 & 16588.19845 & 0.198409735 & 1186.875185 & 0.182954322 & 0.508223368 & 4.764283899 \\
\hline 13-Sep-07 & 25-Oct-07 & 17295.41729 & 0.194706798 & 325.6152478 & 0.297277594 & -0.983474273 & 10.07140551 \\
\hline 17-Sep-07 & 25-Oct-07 & 23140.15157 & 0.193442793 & 9.261525815 & 0.185361413 & -0.270486098 & 1.09183015 \\
\hline 19-Sep-07 & 25-Oct-07 & 42622.0652 & 0.210323665 & 1043.873968 & 0.186192854 & 0.223479441 & -0.515184411 \\
\hline 21-Sep-07 & 25-Oct-07 & 49777.50688 & 0.187335924 & 3959.685787 & 0.20636702 & 0.845542987 & 7.771007336 \\
\hline 25-Sep-07 & 25-Oct-07 & 26850.46777 & 0.220757391 & 3632.730714 & 0.630504493 & 1.636151396 & 13.64128097 \\
\hline 01-Oct-07 & $25-O c t-07$ & 51159.54959 & 0.23680282 & 652.0953917 & 0.230711499 & -0.891869967 & -0.300833878 \\
\hline 04-Oct-07 & 25-Oct-07 & 16827.83974 & 0.257052229 & 3783.990284 & 0.227174056 & -0.564526729 & 2.663369987 \\
\hline 08-Oct-07 & $25-O c t-07$ & 4619.269149 & 0.308464606 & 3270.476348 & 0.28156063 & -0.874079836 & 3.624433127 \\
\hline 10-Oct-07 & 25-Oct-07 & 15873.11113 & 0.316287833 & 14587.7481 & 0.310515665 & -0.669919981 & 2.314873149 \\
\hline $12-$ - ct-07 & 25-Oct-07 & 10227.90974 & 0.35044309 & 9994.201691 & 0.304810038 & -0.652502455 & 5.641813353 \\
\hline $16-$ Oct-07 & 25-Oct-07 & 9071.745112 & 0.382296023 & 6002.89684 & 0.367113463 & -1.537935272 & 4.662973066 \\
\hline 18-Oct-07 & $25-$ Oct-07 & 10575.53459 & 0.407934706 & 11910.81317 & 0.313228748 & -0.567909754 & -0.003820752 \\
\hline 22-Oct-07 & 25-Oct-07 & 18142.16201 & 0.506001568 & 6954.726385 & 0.373287352 & 0.034676262 & 3.557241188 \\
\hline 05-Sep-07 & 29-Nov-07 & 4432.286627 & 0.170201607 & 496.7397359 & 0.232568702 & 2.185911954 & 2.813007118 \\
\hline 11-Sep-07 & 29-Nov-07 & $1.26963 \mathrm{E}-18$ & 13338.55904 & 0 & 0.188072868 & 2.011495679 & 2.987036955 \\
\hline 14-Sep-07 & 29-Nov-07 & 4210.198137 & 0.197395971 & 1057.314135 & 0.16114617 & 1.820778937 & 3.187688372 \\
\hline 01-Oct-07 & 29-Nov-07 & 88.8369657 & 0.220402452 & 88.71934226 & 0.201692046 & -0.790082127 & -0.076654269 \\
\hline 04-Oct-07 & 29-Nov-07 & 330.4163573 & 0.250588352 & 77.65432153 & 0.189138562 & -1.024863272 & -1.073092029 \\
\hline $12-$ Oct-07 & 29-Nov-07 & 680.0303735 & 0.291539505 & 209.29181 & 0.435122662 & -0.501176589 & 9.865252808 \\
\hline $16-$ Oct-07 & 29-Nov-07 & 1450.441529 & 0.331122876 & 825.5637678 & 0.381138556 & -0.596131803 & 3.940308769 \\
\hline 18-Oct-07 & 29-Nov-07 & 1527.895054 & 0.364658683 & 894.8321757 & 0.34959633 & -1.196699546 & 0.795316114 \\
\hline 22-Oct-07 & 29-Nov-07 & 5968.120859 & 0.387403218 & 3168.100335 & 0.813332739 & -1.49727559 & 12.22853378 \\
\hline 24-Oct-07 & 29-Nov-07 & 16968.27858 & 0.345191171 & 11278.17524 & 0.626406123 & -0.796780204 & 5.925996473 \\
\hline
\end{tabular}

